\title{
The Association Between Geographic Location and Anxiety and Depression in Transgender Individuals: An Exploratory Study of an Online Sample
}

\author{
Morgan T. Sinnard, ${ }^{*}$ Christopher R. Raines, and Stephanie L. Budge
}

\begin{abstract}
Purpose: Research has demonstrated associations between discrimination and mental health in lesbian, gay, bisexual, and transgender populations. However, little is known about the influence of geographic location on psychological distress in these populations, particularly among transgender people.

Methods: This secondary analysis conducted on a national sample of transgender individuals $(N=414)$ offers a preliminary understanding of the effects of geographic location on psychological distress (i.e., anxiety and depression). A univariate analysis of variance was calculated to determine this relationship.

Results: The West South Central division (i.e., Arkansas, Louisiana, Oklahoma, and Texas) revealed highest psychological distress.

Conclusion: Results suggest an urgent need for transgender-competent healthcare in this division.
\end{abstract}

Keywords: health disparities; mental health needs; minority stress; transgender

\section{Introduction}

Meyer's minority stress theory posits that minority populations face substantial social stigma and discrimination, resulting in chronic stress and comparatively poor mental health. ${ }^{1}$ Geographic location has been identified as a predictor of heterosexist discrimination. ${ }^{2}$ However, the relationship between minority stress and geographic location among lesbian, gay, bisexual, and transgender (LGBT) populations has not been extensively researched. The literature is nascent on the intersection of geographic location and minority stress among transgender people, who as a population suffer from disproportionately high rates of anxiety and depression., ${ }^{3,4}$

Minority stress in LGBT individuals has been researched in nationwide and statewide samples. ${ }^{5-8}$ Scarce research exists regarding minority stress as a function of geographic location, yet this is an important area for consideration. In the first large-scale study of its kind, Tilcsik explored employment discrimination against openly gay men in the United States. ${ }^{9}$ Pairs of false resumes-one including experience in a gay campus organization and the other a control organization-were sent to potential employers in seven states, and heterosexist discrimination was assessed. Significant regional variations were reported regarding interview invitations $(p<0.001)$. South and Midwest states (e.g., Texas, Florida, and Ohio) revealed greater discrimination, whereas West and Northeast states (e.g., California, New York, and Pennsylvania) demonstrated little to no discrimination. ${ }^{9}$ Another study found that transgender youth living in the South or the Midwest were more likely to experience victimization based on their gender expression. Results of the study suggest that transphobic discrimination varies geographically, and may reflect regional attitudes and antidiscrimination laws. ${ }^{10}$

Heterosexist and transphobic discrimination have also been researched at the national level. Swank et al. examined the stigmatization of LGB individuals in rural and urban locations across the United States. Compared with their urban counterparts, rural LGB respondents

Department of Counseling Psychology, University of Wisconsin-Madison, Madison, Wisconsin.

*Address correspondence to: Morgan T. Sinnard, MEd, Department of Counseling Psychology, University of Wisconsin-Madison, 1000 Bascom Mall, Education Building 335, Madison, WI 53706, E-mail: sinnard@wisc.edu

(c) Morgan T. Sinnard et al. 2016; Published by Mary Ann Liebert, Inc. This Open Access article is distributed under the terms of the Creative Commons License (http://creativecommons.org/licenses/by/4.0), which permits unrestricted use, distribution, and reproduction in any medium, provided the original work is properly credited. 
reported higher frequencies of verbal harassment and discrimination both in housing and employment. ${ }^{2}$ Relatedly, Lee and Quam studied the rural and urban experiences of 690 LGBT baby boomers, of which only $10.1 \%$ of the rural sample and $2.3 \%$ of the urban sample identified as transgender. Overall, rural participants reported higher levels of guardedness with both siblings and close friends, and lower levels of outness. ${ }^{11}$ Similar findings of

Table 1. Demographic Characteristics of Participants

\begin{tabular}{|c|c|c|}
\hline Characteristic & Level & $n(\%)$ \\
\hline Region & Northeast & \\
\hline \multirow{13}{*}{$\begin{array}{l}\text { Division } \\
\text { States }\end{array}$} & 1. New England & $45(10.9)$ \\
\hline & $\begin{array}{l}\text { Connecticut, Maine, } \\
\text { Massachusetts, } \\
\text { New Hampshire, } \\
\text { Rhode Island, } \\
\text { Vermont }\end{array}$ & \\
\hline & $\begin{array}{l}\text { 2. Middle Atlantic } \\
\text { New Jersey, New York, } \\
\text { Pennsylvania }\end{array}$ & $42(10.1)$ \\
\hline & Midwest & \\
\hline & $\begin{array}{l}\text { 3. East North Central } \\
\text { Indiana, Illinois, } \\
\text { Michigan, Ohio, Wisconsin }\end{array}$ & $88(21.3)$ \\
\hline & $\begin{array}{l}\text { 4. West North Central } \\
\text { lowa, Kansas, } \\
\text { Minnesota, Missouri, } \\
\text { Nebraska, North Dakota, } \\
\text { South Dakota }\end{array}$ & $38(9.2)$ \\
\hline & South & \\
\hline & $\begin{array}{l}\text { 5. South Atlantic } \\
\text { Delaware, District of } \\
\text { Columbia, Florida, } \\
\text { Georgia, Maryland, } \\
\text { North Carolina, } \\
\text { South Carolina, } \\
\text { Virginia, West Virginia }\end{array}$ & $37(8.9)$ \\
\hline & $\begin{array}{l}\text { 6. East South Central } \\
\text { Alabama, Kentucky, } \\
\text { Mississippi, Tennessee }\end{array}$ & $13(3.1)$ \\
\hline & $\begin{array}{l}\text { 7. West South Central } \\
\text { Arkansas, Louisiana, } \\
\text { Oklahoma, Texas }\end{array}$ & $31(7.5)$ \\
\hline & West & \\
\hline & $\begin{array}{l}\text { 8. Mountain } \\
\text { Arizona, Colorado, } \\
\text { Idaho, New Mexico, } \\
\text { Montana, Utah, Nevada, } \\
\text { Wyoming }\end{array}$ & $32(7.7)$ \\
\hline & $\begin{array}{l}\text { 9. Pacific } \\
\text { Alaska, California, } \\
\text { Hawaii, Oregon, } \\
\text { Washington }\end{array}$ & $88(21.3)$ \\
\hline \multirow[t]{6}{*}{ Race } & White, not Hispanic & $361(87.6)$ \\
\hline & Black/African American & $4(1.0)$ \\
\hline & Native American & $3(0.70)$ \\
\hline & Asian/Pacific Islander/Asian American & $6(1.5)$ \\
\hline & Hispanic/Latino & $9(2.2)$ \\
\hline & Multiracial & $29(7.0)$ \\
\hline \multirow[t]{4}{*}{ Trans ID } & Trans woman & $211(52.0)$ \\
\hline & Trans man & $114(28.1)$ \\
\hline & Genderqueer & $60(14.8)$ \\
\hline & Cross-dresser & $20(4.9)$ \\
\hline
\end{tabular}

a qualitative investigation by Oswald and Culton, of which less than $1 \%$ of the sample identified as transgender, suggest that rural LGBT individuals experience greater community homophobia, inadequate social support, and more frequent civil rights discrimination than their urban counterparts. ${ }^{12}$

Transgender individuals face significant barriers to accessing healthcare, and are less likely to have health insurance and a primary care physician than cisgender individuals. ${ }^{13}$ The first study to directly compare mental health, substance use, and sexual risk behaviors of rural and nonrural transgender individuals found that rural transgender men experienced the greatest barriers to healthcare and the greatest need for mental healthcare services. ${ }^{14}$ A study among urban transgender women in New York City found high rates of healthcare utilization, with the majority of participants having health insurance $(77 \%)$ and seeing a general practitioner within the past year $(81 \%) .{ }^{15}$ However, one in four participants reported that the high cost of medical care, limited access to specialists, and scarcity of transgender-friendly and knowledgeable providers were substantial barriers to care. ${ }^{15}$ Taken together, these two studies highlight the need for healthcare providers across the United States to reduce barriers to care for transgender patients, particularly in rural locations.

A review of the literature suggests geographic variations of heterosexist discrimination in LGB populations. Little is known about regional variations of transphobic discrimination against transgender individuals, specifically. Although our study does not examine regional variations of antitransgender discrimination, we sought to understand whether regional variations of psychological distress (i.e., anxiety and depression) exist for transgender individuals in the United States. This study is a secondary analysis of an existing database that aims to examine the role of geographic location on anxiety and depression scores of transgender individuals.

\section{Methods}

\section{Participants and procedures}

The data set for the present analysis was drawn from a database previously used to investigate research questions related to coping, social support, loss, and psychological distress in transgender individuals. Specific procedures are described in the original publication. ${ }^{16}$

Demographics. Participants $(N=414)$ ranged in age from 18 to $78(M=39.58, S D=14.41)$. The majority of participants identified as non-Hispanic white $(87.6 \%)$ 
and as transgender women (51.7\%). Participants selfreported their gender identity label by responding to an open-ended question. Two researchers coded gender identity responses for classification as transgender man, transgender woman, gender queer, or crossdresser. Inter-rater reliability was $100 \%$. A detailed description of participant demographics is given in Table 1.

Transgender individuals were recruited through social networking sites and university and community LGBT centers to complete an online survey. Written informed consent was obtained from participants. All procedures were reviewed and approved by the Institutional Review Board at a large Midwest university. After collection, data were separated into geographic zones according to respondent residential location. These zones were obtained from the United States Census Bureau, which separates the United States into four geographic regions (Northeast, Midwest, South, and West.); the United States Census Bureau further divides these regions into nine total divisions for data collection and analysis purposes (New England, Middle Atlantic, East North Central, West North Central, South Atlantic, East South Central, West South Central, Mountain, and Pacific).

\section{Measures}

We used the 20-item Center for Epidemiologic Studies Depression (CES-D) scale to measure depressive symptoms. Scores range from 0 to 60 , with higher scores indicating greater depressive symptoms. The scale has high internal consistency ( 0.85 to 0.90$)$ and moderate test-retest stability (between 0.45 and 0.70 ). ${ }^{17}$ Past research has demonstrated the appropriate use of the scale with transgender populations. ${ }^{18,19}$

To measure symptoms of anxiety, we used the Burns Anxiety Inventory (BAI). The BAI is a 33-item selfreport measure organized into three categories: anxious thoughts, anxious feelings, and somatic symptoms. Scores range from 0 to 99 , with higher scores indicating greater anxious symptoms. ${ }^{20}$ The measure has been found to have an internal consistency from 0.92 to $0.94^{20,21}$

\section{Results}

We first calculated mean BAI score across all measured locations $(M=22.61, S D=18.05)$. A univariate analysis of variance (ANOVA) was calculated on participant BAI scores according to geographic location. The analysis was significant, $F(8,347)=2.62, p=0.008, \eta_{\mathrm{p} 2}=0.057$.
Pairwise comparisons were conducted between the nine divisions of the United States.

We then calculated mean CES-D scores across all measured locations $(M=22.80, S D=8.63)$. A univariate ANOVA was calculated on participant CES-D scores according to geographic location. The analysis was not significant $(p=0.110)$. Pairwise comparisons were conducted between the nine divisions of the United States.

\section{Effects of location on levels of anxiety}

\section{and depression}

Anxiety levels were significantly higher in the West South Central division than in the Middle Atlantic $(p=0.026)$, West North Central $(p=0.001)$, South Atlantic $(p=0.000)$, and Pacific $(p=0.018)$ divisions. Participants living in the Pacific division reported significantly higher levels of anxiety than those in the South Atlantic division $(p=0.039)$. Participants in New England reported significantly higher levels of anxiety than those in West North Central $(p=0.029)$ and South Atlantic $(p=0.011)$. Similar results were found for participants living in the East North Central division, who reported significantly higher levels of anxiety than those living in West North Central $(p=0.016)$ and South Atlantic $(p=0.005)$.

Depression levels were significantly higher in the West South Central division of the United States than in Middle Atlantic $(p=0.043)$, West North Central $(p=0.005)$, South Atlantic $(p=0.006)$, and Pacific $(p=0.021)$ divisions. Participants in New England revealed significantly higher depression levels than those in West North Central $(p=0.049)$. Means, standard errors, and mean differences of BAI scores by location and CES-D scores by location are presented in Table 2.

There was a significant correlation between depression and location in the West South Central division $(r=0.121, p<0.05)$. There was a significant correlation between anxiety and location in the West North Central division $(r=-0.115, p<0.05)$, the South Atlantic division $(r=-0.140, p<0.01)$, and the West South Central division $(r=0.144, p<0.01)$. Depression and anxiety levels were strongly correlated, $r(333)=0.783$, $p<0.01$. This relationship was expected because of the comorbidity of anxiety and depression. ${ }^{20}$

\section{Discussion}

Preliminary findings suggest that transgender individuals living in the West South Central division of the United States (i.e., Arkansas, Louisiana, Oklahoma, and Texas) 
Table 2. Means, Standard Errors, and Mean Differences of BAI Scores and CES-D Scores by Location

\begin{tabular}{|c|c|c|c|c|c|c|c|c|c|c|c|c|}
\hline & M & SEM & $95 \% \mathrm{Cl}$ & 1 & 2 & 3 & 4 & 5 & 6 & 7 & 8 & 9 \\
\hline \multicolumn{13}{|c|}{ 1. New England } \\
\hline BAl & 25.53 & 2.95 & $19.72,31.34$ & 0 & & & & & & & & \\
\hline CES-D & 24.21 & 1.31 & $21.64,26.78$ & 0 & & & & & & & & \\
\hline \multicolumn{13}{|c|}{ 2. Middle Atlantic } \\
\hline BAI & 21.73 & 2.91 & $16.00,27.46$ & -3.80 & 0 & & & & & & & \\
\hline CES-D & 22.18 & 1.37 & $19.48,24.88$ & -2.03 & 0 & & & & & & & \\
\hline \multicolumn{13}{|c|}{ 3. East North Central } \\
\hline BAl & 25.08 & 2.01 & $21.13,29.03$ & -0.45 & 3.35 & 0 & & & & & & \\
\hline CES-D & 23.57 & 0.94 & $21.72,25.42$ & -0.64 & 1.39 & 0 & & & & & & \\
\hline \multicolumn{13}{|c|}{ 4. West North Central } \\
\hline BAl & 16.24 & 3.04 & $10.26,22.22$ & $-9.29^{*}$ & -5.49 & $-8.84^{*}$ & 0 & & & & & \\
\hline CES-D & 20.39 & 1.43 & $17.58,23.20$ & $-3.82^{*}$ & -1.79 & -3.18 & 0 & & & & & \\
\hline \multicolumn{13}{|c|}{ 5. South Atlantic } \\
\hline BAl & 14.30 & 3.24 & $7.93,20.67$ & $-11.23^{*}$ & -7.43 & $-10.78^{*}$ & -1.94 & 0 & & & & \\
\hline CES-D & 20.38 & 1.52 & $17.39,23.36$ & -3.83 & -1.80 & -3.19 & -0.01 & 0 & & & & \\
\hline \multicolumn{13}{|c|}{ 6. East South Central } \\
\hline BAI & 20.15 & 4.92 & $10.48,29.82$ & -5.37 & -1.58 & -4.92 & 3.92 & 5.85 & 0 & & & \\
\hline CES-D & 22.82 & 2.59 & $17.73,27.90$ & -1.39 & 0.64 & -0.75 & 2.43 & 2.44 & 0 & & & \\
\hline \multicolumn{13}{|c|}{ 7. West South Central } \\
\hline BAl & 31.89 & 3.48 & $25.05,38.72$ & 6.36 & $10.16^{*}$ & 6.81 & $15.65^{*}$ & $17.59^{*}$ & 11.73 & 0 & & \\
\hline CES-D & 26.50 & 1.62 & $23.31,29.69$ & 2.29 & $4.32^{*}$ & 2.93 & $6.11^{*}$ & $6.13^{*}$ & 3.68 & 0 & & \\
\hline \multicolumn{13}{|c|}{ 8. Mountain } \\
\hline BAl & 23.18 & 3.35 & $16.59,29.77$ & -2.35 & 1.45 & -1.90 & 6.94 & 8.88 & 3.03 & -8.71 & 0 & \\
\hline CES-D & 23.23 & 1.57 & $20.15,26.31$ & -0.98 & 1.05 & -0.33 & 2.84 & 2.86 & 0.42 & -3.23 & 0 & \\
\hline \multicolumn{13}{|l|}{ 9. Pacific } \\
\hline BAI & 22.27 & 2.06 & $18.22,26.32$ & -3.26 & 0.54 & -2.81 & 6.04 & $7.97^{*}$ & 2.12 & $-9.61^{*}$ & -0.91 & 0 \\
\hline CES-D & 22.15 & 0.96 & $20.27,24.04$ & -2.06 & -0.03 & -1.42 & 1.76 & 1.78 & -0.67 & $-4.35^{*}$ & -1.08 & 0 \\
\hline
\end{tabular}

${ }^{*} p<0.05$.

BAl, Burns Anxiety Inventory; CES-D, Center for Epidemiologic Studies Depression Scale; Cl, confidence interval.

experience higher levels of both anxiety and depression than many of their transgender counterparts living elsewhere. It is possible that these findings arose because of the historically conservative values in the West South Central division, compounding minority stress. ${ }^{22,23}$

Importantly, gender role attitudes have been found to vary regionally in the United States. Individuals living in the South region of the nation have been found to endorse more traditional attitudes toward gender roles than people residing elsewhere. ${ }^{24}$ This distinct cultural value may contribute to a hostile climate for transgender individuals, who challenge the established gender binary, and may help explain why our respondents in the West South Central division reported higher levels of anxiety and depression. To our knowledge, there does not currently exist any literature about the effects of sociopolitical conservatism on the mental health of marginalized populations.

\section{Limitations}

Our study has several limitations that should be considered when interpreting the findings. Although online surveys are important for accessing less visible identities and decentralized populations, inequities in Internet access preclude some individuals from participation. Because our data were drawn from an online cross-sectional sample, no causality inferences may be made. Our sample was rather homogeneous regarding racial identification $(87.1 \%$ white, nonHispanic) and gender identity (51.7\% transgender women); therefore, our results should not be generalized to all transgender people, particularly transgender individuals of color.

Disparities in access to healthcare exist between urban and rural areas as well as broader geographic regions of the United States. ${ }^{25}$ Importantly, the intersecting forces of gender, race, and geographic region have been found to influence clinical health outcomes. A recent nationwide study among individuals with HIV revealed that people of color and individuals living in the South had elevated HIV-related morbidity than their white, non-Southern counterparts. ${ }^{26}$ Similarly, race was a crucial factor in a study among transgender men living in rural areas of the Midwest 
and Southeast United States. ${ }^{27}$ The qualitative research indicated that white transgender men found acceptance in rural communities based on their race and performance of rural working-class masculinity. Although results of the study suggest a reduction in transphobia against white transgender men, the same acceptance was not found for transgender individuals of color. ${ }^{27}$

A major limitation of our study is the lack of a geographically defined control group. Without this, we cannot conclusively establish a difference between transgender residents and the general population. It is important to consider the possibility that depression and anxiety may be higher in the West South Central division among all residents, not just among transgender individuals. There may in fact be unmeasured confounders contributing to the high rates of anxiety and depression that were not accounted for in our study. As such, we emphasize that our findings are considered preliminary and further research is needed to confirm or disconfirm our results.

\section{Conclusions}

It is urgent that discriminatory attitudes against transgender individuals in the West South Central division of the United States are confronted, particularly in rural areas. Moving forward, we recommend greater and nuanced attention paid to improving mental healthcare services for transgender individuals in the West South Central division (Texas, Arkansas, Oklahoma, and Louisiana). For instance, we recommend mental healthcare providers work to increase access to gender-informed care for transgender individuals as well as their families. Furthermore, increasing the visibility of transgender-competent healthcare providers in the transgender community is critical to ensuring their healthcare needs are met, particularly in rural areas. Future research should examine access to and quality of healthcare among transgender people, especially transgender individuals of color, in the West South Central division of the United States.

\section{Acknowledgments}

We would like to thank Kevin Chapman, $\mathrm{PhD}$, and Rich Lewine, $\mathrm{PhD}$, for their contributions to this article. This study was reviewed and approved by the Institutional Review Board of a large Midwestern university. The ethical standards of the Institutional Review Board were adhered to throughout the entire study.

\section{Disclaimer}

This is a secondary analysis of a database that has been previously used to investigate research questions related to coping, social support, loss, and psychological distress in transgender individuals. Parts of this article were previously presented for the fulfillment of an Honors undergraduate thesis.

\section{Author Disclosure Statement}

No competing financial interests exist.

\section{References}

1. Meyer IH. Prejudice, social stress, and mental health in lesbian, gay, and bisexual populations: conceptual issues and research evidence. Psychol Bull. 2003;129:674-697.

2. Swank E, Fahs B, Frost DM. Region, social identities, and disclosure practices as predictors of heterosexist discrimination against sexual minorities in the United States. Sociol Inq. 2013;83:238-258.

3. Bockting WO, Miner MH, Swinburne-Romine RE, et al. Stigma, mental health, and resilience in an online sample of the US transgender population. Am J Public Health. 2013;103:943-951.

4. Yang MF, Manning D, van den Berg JJ, Operario D. Stigmatization and mental health in a diverse sample of transgender women. LGBT Health. 2015;2:306-312.

5. Baams L, Grossman AH, Russell ST. Minority stress and mechanisms of risk for depression and suicidal ideation among lesbian, gay, and bisexual youth. Dev Psychol. 2015;51:688-696.

6. Carter LW, Mollen D, Smith NG. Locus of control, minority stress, and psychological distress among lesbian, gay, and bisexual individuals. J Couns Psychol. 2014;61:169-175.

7. McCarthy MA, Fisher CM, Irwin JA, et al. Using the minority stress model to understand depression in lesbian, gay, bisexual, and transgender individuals in Nebraska. J Gay Lesbian Ment Health. 2014;18:346-360.

8. Taylor P. A survey of LGBT Americans: Attitudes, experiences, and values in changing times. Washington, DC: Pew Research Center, 2013.

9. Tilcsik A. Pride and prejudice: employment discrimination against openly gay men in the United States. Am J Sociol. 2011;117:586-626.

10. Kosciw JG, Greytak EA, Diaz EM. Who, what, where, when, and why: demographic and ecological factors contributing to hostile school climate for lesbian, gay, bisexual, and transgender youth. J Youth Adolesc. 2009;38:976-988.

11. Lee MG, Quam JK. Comparing supports for LGBT aging in rural versus urban areas. J Gerontol Soc Work. 2013;56:112-126.

12. Oswald RF, Culton LS. Under the rainbow: rural gay life and its relevance for family providers. Family Relat. 2003;52:72-81.

13. dickey Im, Budge SL, Katz-Wise SL, Garza MV. Health disparities in the transgender community: exploring differences in insurance coverage. Psychol Sex Orientat Gend Divers. 2016;3:275-282.

14. Horvath KJ, lantaffi A, Swinburne-Romine R, Bockting W. A comparison of mental health, substance use, and sexual risk behaviors between rural and non-rural transgender persons. J Homosex. 2014;61:1117-1130.

15. Sanchez NF, Sanchez JP, Danoff A. Health care utilization, barriers to care, and hormone usage among male-to-female transgender persons in New York City. Am J Public Health. 2009;99:713-719

16. Budge SL, Adelson JL, Howard KA. Anxiety and depression in transgender individuals: the roles of transition status, loss, social support, and coping J Consult Clin Psychol. 2013;81:545-557

17. Radloff LS. The CES-D scale: a self-report depression scale for research in the general population. Appl Psychol Meas. 1977;1:385-401.

18. Clements-Nolle K, Marx R, Katz M. Attempted suicide among transgender persons: the influence of gender-based discrimination and victimization. J Homosex. 2006;51:53-69.

19. Cochran BN, Stewart AJ, Ginzler JA, Cauce AM. Challenges faced by homeless sexual minorities: comparison of gay, lesbian, bisexual, and transgender homeless adolescents with their heterosexual counterparts. Am J Public Health. 2002;92:773-777. 
20. Burns DD, Eidelson RJ. Why are depression and anxiety correlated? A test of the tripartite model. J Consult Clin Psychol. 1998;66:461-473.

21. Kring AM, Persons JB, Thomas $C$. Changes in affect during treatment for depression and anxiety. Behav Res Ther. 2007;45:1753-1764.

22. Ellison CG, Musick MA. Southern intolerance: a fundamentalist effect? Soc Forces. 1993;72:379-398.

23. Lowndes JE. From the New Deal to the New Right: Race and the Southern Origins of Modern Conservatism. New Haven: Yale University Press, 2008

24. Carter JS, Borch CA. Assessing the effects of urbanism and regionalism on gender-role attitudes. Sociol Inq. 2005;75:548-563.

25. Arcury TA., Gesler WM, Preisser JS, et al. The effects of geography and spatial behavior on health care utilization among the residents of a rural region. Health Serv Res. 2005:40:135-156.

26. Meditz AL, MaWhinney S, Allshouse A, et al. Sex, race, and geographic region influence clinical outcomes following primary HIV-1 infection. $J$ Infect Dis. 2011;203:442-451.

27. Abelson MJ. 'You aren't from around here': race, masculinity, and rural transgender men. Gend Place Cult. 2016;23:1-12.
Cite this article as: Sinnard MT, Raines CR, Budge SL (2016) The association between geographic location and anxiety and depression in transgender individuals: an exploratory study of an online sample, Transgender Health 1:1, 181-186, DOI: 10.1089/trgh.2016.0020.

\section{Abbreviations Used}

ANOVA $=$ analysis of variance

$\mathrm{BAI}=$ Burns Anxiety Inventory

CES-D $=$ Center for Epidemiologic Studies Depression $\mathrm{Cl}=$ confidence interval

$\mathrm{LGBT}=$ lesbian, gay, bisexual, and transgender

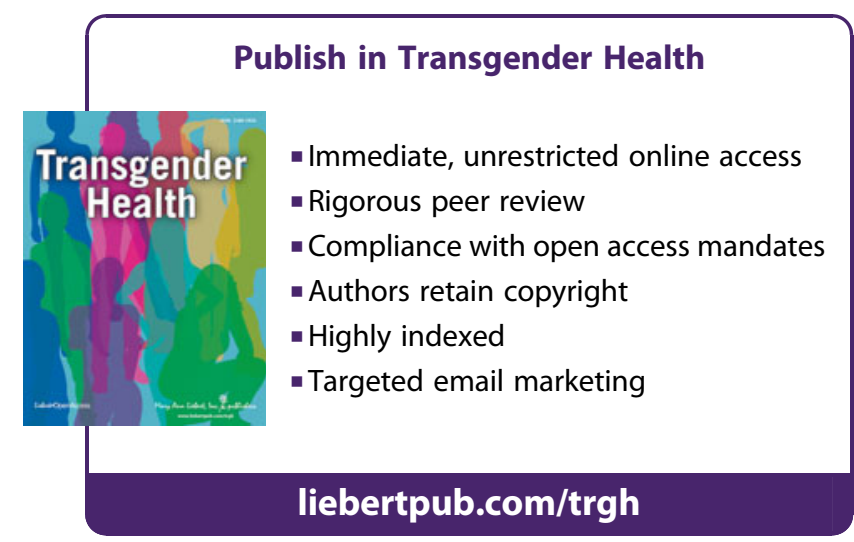

